\title{
Tuning Characteristics of Reentrant Klystron Cavities
}

\author{
Joaquim J. Barroso and Joaquim P. Leite Neto \\ Associated Plasma Laboratory, National Institute for Space Research - INPE \\ 12201-970 São José dos Campos, SP, Brazil
}

\begin{abstract}
The present paper examines how the resonance frequency $f_{0}$ and the electrical $Q$ factor relate to the geometrical shape of the coaxial insert in reentrant klystron cavities. Through proper selection of the geometry of the coaxial conductor (either circular cylinders or truncated cones), a tuning coefficient as high as $1.0 \mathrm{GHz} / \mu \mathrm{m}$ can be obtained at resonance frequencies around $10.0 \mathrm{GHz}$.
\end{abstract}

Keywords: reentrant cavities; tunable resonators; electromechanical sensors.

\section{Introduction}

Having a simple mechanical construction and wide tuning range, narrow gap reentrant cylindrical cavities were originally investigated during the development years of the klystron [1] and have since then been widely used for the construction of microwave oscillators. These cavities allow the realization of resonant fre-quencies in the low $\mathrm{GHz}$ range without the need for large physical dimensions, with the ridged gap having the effect of reducing the frequency and focusing the electric field (Fig.1). By providing a well-defined electric field in the gap region, such cavities also find a wide range of applications [2], namely, in particle accelerators, solidstate micro-wave oscillators, tunable resonators, characteri-zation of dielectrics, measurement of semiconductor parameters, micro-wave scanning microscopy, electron spin resonance spectroscopy, susceptibility measurements, microwave tubes, and electromechanical sensors of gravitational waves

A reentrant cavity, as viewed in Fig. 1, is basically an LC resonator where the equivalent capacitance is determined by the gap spacing between the coaxial post (radius $r_{1}$ ) and the top closing plate (radius $r_{2}$ ), with the inductance being mainly due to coaxial region $\left(\mathrm{r}_{2}-\mathrm{r}_{1}\right)$ of the cavity. Since the exact solutions of Maxwell's equations inside the resonator configuration are not known, the properties of interest (resonance frequency, and quality $\mathrm{Q}$ factor) must be calculated numerically. By using the code Superfish [3], the present paper examines how the resonance frequency $f_{0}$ and the electrical Q factor relate to the geometrical shape of the coaxial insert. The cavities examined here are developmental replicas of electromechanical transducers to be instrumented in a gravitational wave antenna, the Schenberg detector, currently under tests [4]. Through proper selection of the geometry of the coaxial conductor (either circular cylinders or truncated cones), a tuning coefficient as high as 1.0 $\mathrm{GHz} / \mu \mathrm{m}$ can be obtained at resonance frequencies around $10.0 \mathrm{GHz}$.
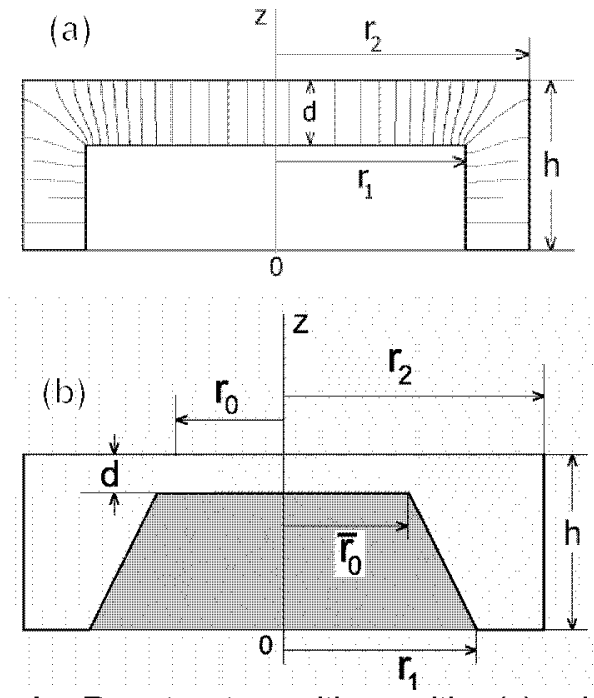

Figure 1. Reentrant cavities with (a) circular cylindrical and (b) conical inserts

This tuning effect is particularly important in electromagnetic cavity-based transducers that operate at high $\Delta \mathbf{f}_{0} / \Delta \mathbf{d}$ to maximize the electrical coupling of the reentrant cavity to an external mechanical transformer. A cavity of this sort finds advanced applications in parametric transducers to continually monitor the vibration state of mass gravitational wave antennas through modulation of the capacitive gap [5].

\section{Tuning characteristics and discussion}

We compare in Fig.2 the tuning characteristics arising from three inserts of the same height placed in a cylindrical cavity $8.0 \mathrm{~cm}$ in diameter. The thick cylinder $(\mathrm{rl}=20.0 \mathrm{~mm})$ shows to provide the lowest sensitivity to gap variations, while with tuning curves almost indistinguishable at small gaps $(\mathrm{d}<50 \mu \mathrm{m})$, the thin cylinder and the conical insert produce similar effects concerning frequency tunability. In fact, the corresponding tuning curves relating resonance frequency to axial gap are nearly superimposed up to $d=$ $0.50 \mathrm{~mm}$, and so the thin cylinder is equivalent to the conical insert regarding tuning characteristics. This equivalence, however, does not hold as far as loss effects are concerned, with the conical insert providing higher Q factors than those obtained with the thin cylinder. To illustrate this point, and assuming an electrical conductivity of $5.810^{8} \mathrm{~S} / \mathrm{m}$, we see in Fig. 4 that for $\mathrm{d}>0.5 \mathrm{~mm}$ the $\mathrm{Q}$ factors corresponding to the conical post are systematically 30 percent higher than 
those associated with the thin cylinder. In particular, at $\mathrm{d}=2.0 \mathrm{~mm}$ and considering an electric field strength of $1.0 \mathrm{MV} / \mathrm{m}$ on axis, Table 1 summarizes the relevant parameters $\left(\mathrm{f}_{0}\right.$, Ohmic $\mathrm{Q}$ factor, shunt resistance $\left.\mathrm{R}\right)$ that give a complete characterization of cavity resonators, by noting that, independent of losses, the ratio $R / Q$ is solely determined by the dimensions and geometrical shape of the cavity.

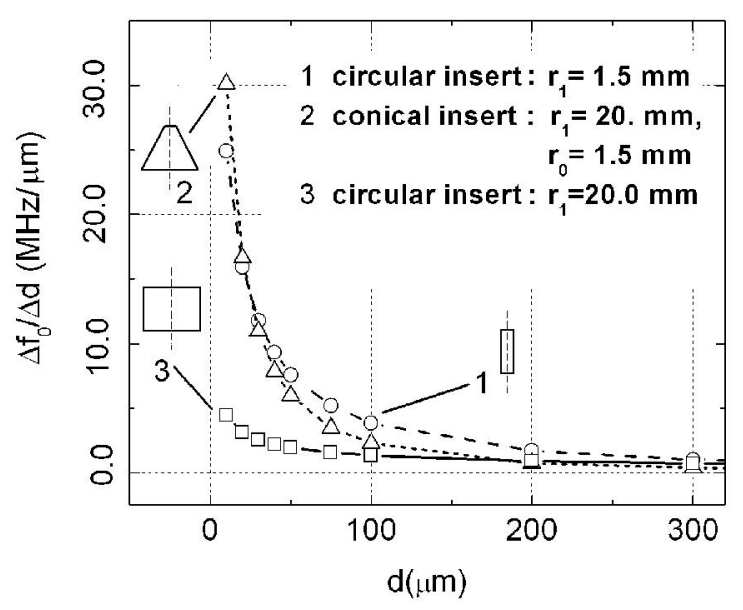

Figure 2. Tuning coefficients relative to three inserts placed in an $8.0-\mathrm{cm}$-diameter circular cylindrical cavity

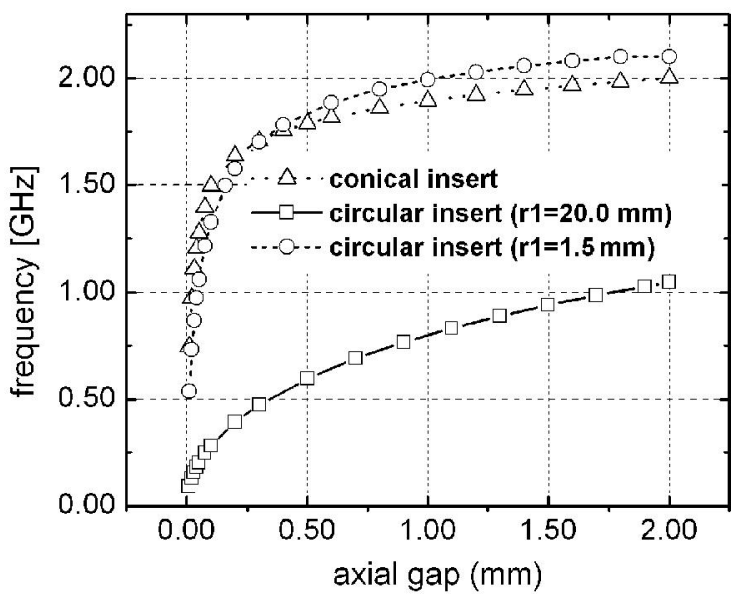

Figure 3. Resonance frequencies as function of the axial gap spacing in reentrant cavities

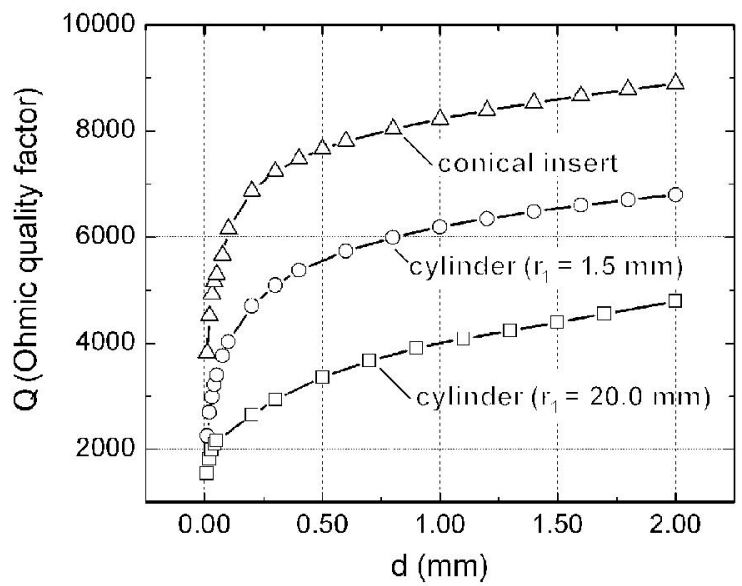

Figure 4. Ohmic $Q$ factors $\left(\sigma=5.810^{8} \mathrm{~S} / \mathrm{m}\right)$ of reentrant cavities as function of the axial gap spacing

Table 1. Properties of reentrant cavities

\begin{tabular}{c|c|c}
\hline posts & $\begin{array}{c}\text { conical } \\
\left(r_{0}=0.15 \mathrm{~cm},\right. \\
\left.r_{1}=2.0 \mathrm{~cm}\right)\end{array}$ & $\begin{array}{c}\text { circular } \\
\text { cylindrical } \\
\left(r_{1}=2.0 \mathrm{~cm}\right)\end{array}$ \\
\hline $\begin{array}{c}\text { quantities } \\
\left(\mathrm{cm}^{3}\right)\end{array}$ & 101.0 & 110.0 \\
\hline $\begin{array}{c}\text { Dissipated } \\
\text { power }(\mathrm{W})\end{array}$ & 2.94 & 1.64 \\
\hline $\begin{array}{c}\text { Stored } \\
\text { energy }(\mu \mathrm{J})\end{array}$ & 2.08 & 0.84 \\
\hline $\begin{array}{c}\text { Frequency } \\
(\mathrm{GHz})\end{array}$ & 2.00 & 2.11 \\
\hline $\mathrm{Q}$ & 8890 & 6810 \\
\hline$\frac{\mathrm{R}}{\mathrm{Q}}(\Omega)$ & 72.6 & 163.3 \\
\hline $\mathrm{R}(\mathrm{M} \Omega)$ & 0.64 & 1.11 \\
\hline
\end{tabular}

\section{References}

1. W. Hansen, J. Appl. Phys., vol. 10, pp. 38-45, 1939.

2. J. J. Barroso, P. J. Castro, J. P. L. Neto, and O. D. Aguiar, Int. J. Infrared Millimeter Waves, vol. 26, no. 8, pp. 1071-1083, August 2005.

3. J. H. Billen and L. M. Young, "Poisson/Superfish", Rep. LA-UR-96-1934, LANL, Los Alamos, NM, 1996.

4. J. J. Barroso, P. J. Castro, O. D. Aguiar, and L. A. Carneiro, Rev. Sci. Instrum., vol. 75, no. 4, pp. 10001005, April 2004.

5. O. D. Aguiar et al., Class. Quantum Grav., vol. 21, no. 5, pp. S457-S463, March 2004 